Portland State University

PDXScholar

\title{
A Biochemical Analysis of Viscin from Arceuthobium tsugense
}

Peter J. Paquet

Portland State University

Follow this and additional works at: https://pdxscholar.library.pdx.edu/open_access_etds

Part of the Biology Commons

Let us know how access to this document benefits you.

\section{Recommended Citation}

Paquet, Peter J., "A Biochemical Analysis of Viscin from Arceuthobium tsugense" (1975). Dissertations and Theses. Paper 2282.

https://doi.org/10.15760/etd.2279

This Thesis is brought to you for free and open access. It has been accepted for inclusion in Dissertations and Theses by an authorized administrator of PDXScholar. Please contact us if we can make this document more accessible: pdxscholar@pdx.edu. 
AN ABSTRACT OF THE THESIS OF Peter J. Paquet for the Master of Science in Biology presented 22 May 1975

Title: A Biochemical Analysis of Viscin from Arceuthobium tsugense

APPROVED BY MEMBERS OF THE THESIS COMMITTEE:
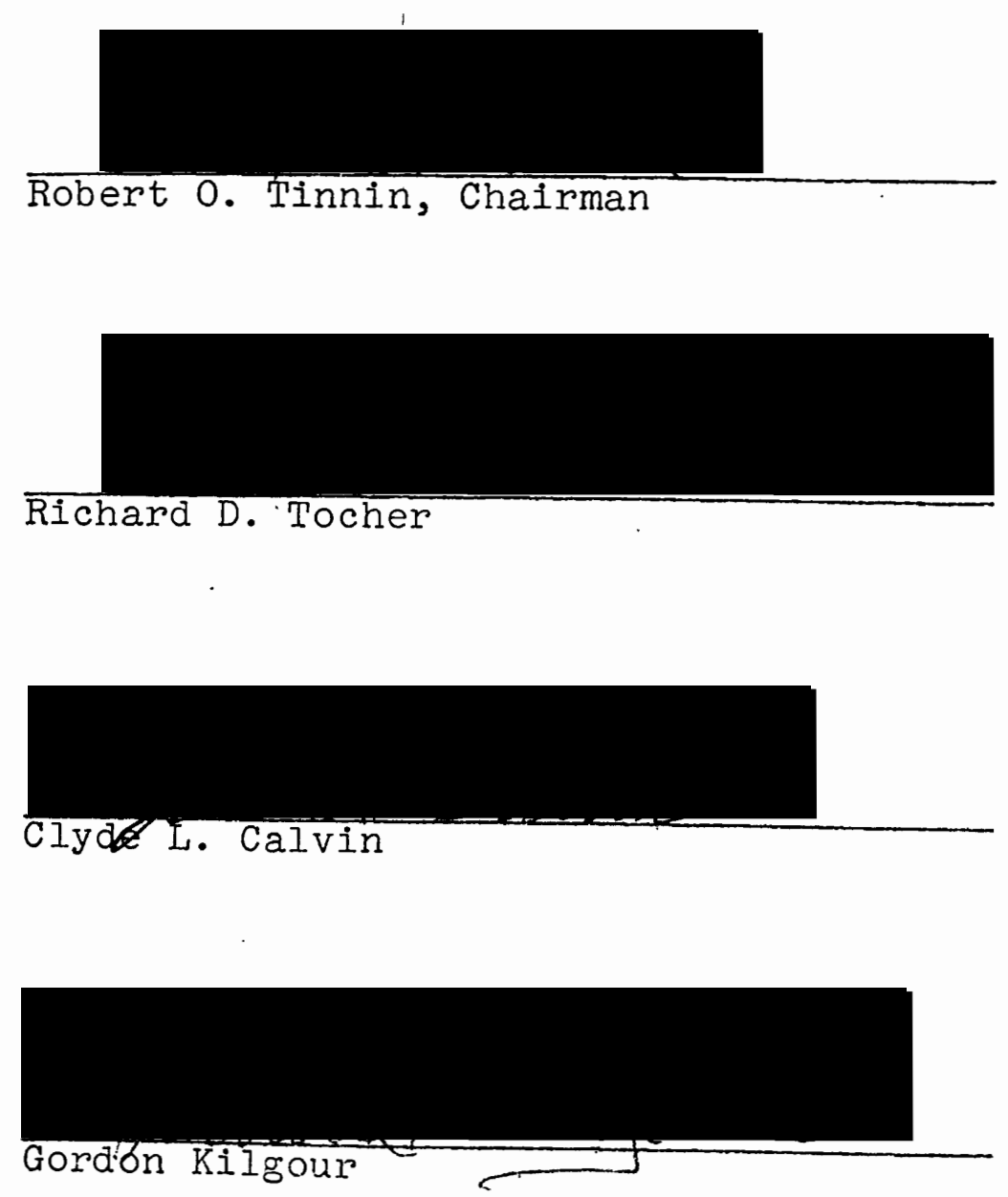

The viscin coating of seeds from Arceuthobium tsugense was analyzed histochemically and enzymatically. The results indicated that the viscin is composed of two components. The first is a muculagenous pectic compound which surrounds the entire seed and accounts for a number of observed 
phenomenon such as stickiness, water holding capacity and the ability to undergo repeated drying and rehydration. The second component is made up of a large number of cellulose strands which are attached to the endocarp and run throughout the pectic coating. Scanning electron micrographs show that they are thought to be important in maintaining the integrity of the pectic coating. The significance of these findings is discussed with respect to establishment of the parasite. 


\section{A BIOCHEMICAL ANALYSIS OF VISCIN FROM}

Arceuthobium tsugerse

by

PETER J. PAQUET

A thesis submitted in partial fulfillment of the requirements for the degree of

\section{MASTER OF SCIENCE \\ in}

BIOLOGY

Portland State University

1.975 
TO THE OFFICE OF GRADUATE STUDIES AND RESEARCH:

The members of the Committee approve the thesis of

Peter J. Paquet presented 22 May 1975.

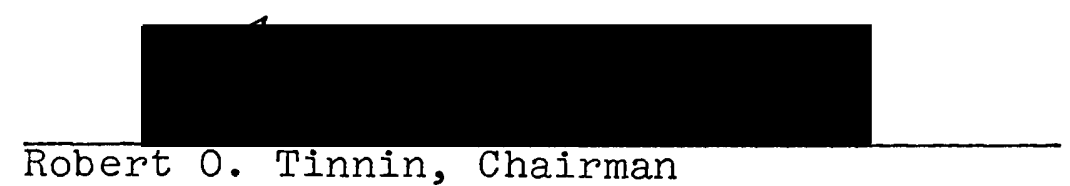

Robert 0. Tinnin, Chairman

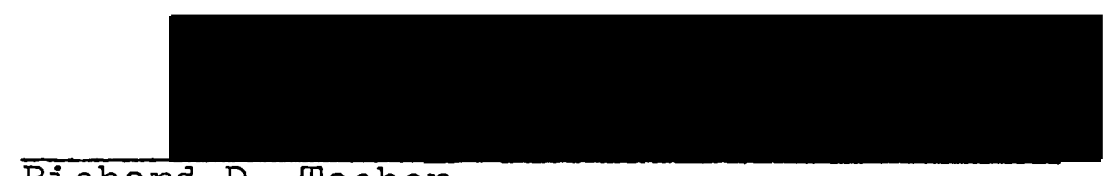

Richard D. Tocher
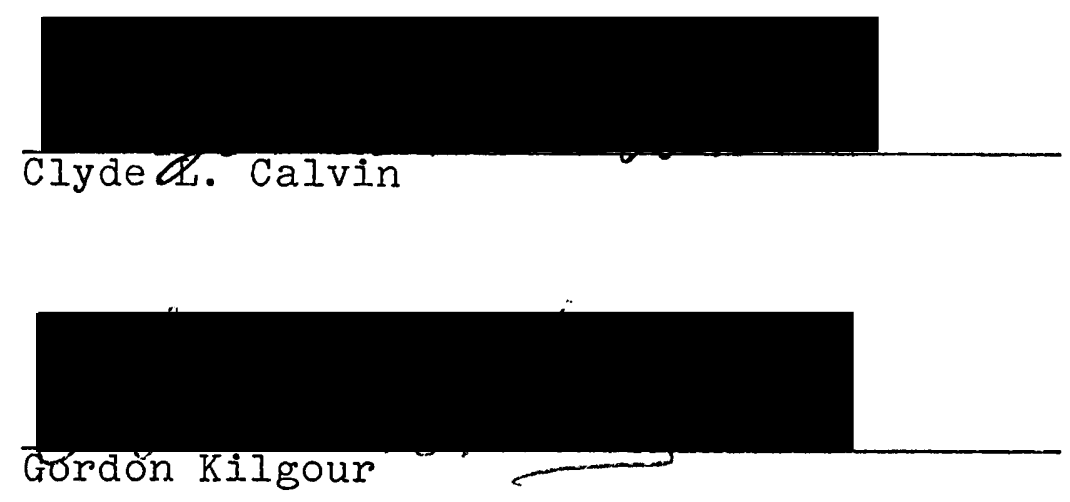

APPROVED :

Eari Fiskér, Jr., Head, Department of Biology

David T. Clark, Dean of Graduate Studies 


\section{ACKNOWLEDGEMENTS}

The author wishes to thank the following individuals for assistance in preparation of this manuscript: Thesis committee members, Drs. Robert Tinnin, Chairman, Richard Tocher, Clyde Calvin, and Gordon Kilgour; my wife, Caroline for her assistance in preparation of the figures; also, my typist, Mary Dozark, without whose assistarce this work would not have been completed. 
ACKNOWLEDGEMENT. ........................ ii

LIST OF FIGURES. . . . . . . . . . .

INTRODUCTION. ......................... 1

MATERIALS AND METHODS................... 3

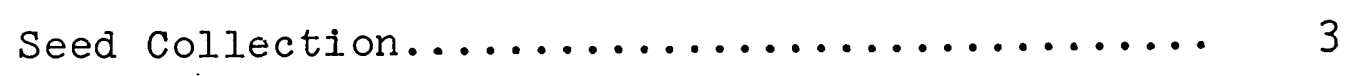

Localization of Carbohydrates in the Viscin

Layer......................... 3

Histochemical Reactions............... 5

Isolation of Pectic Substances............ 6

Determination of Hexuronic Acid........... 8

Enzymatic Hydrolysis................. 8

Acid Hydrolysis.................... 8

Paper Chromatography of Sugars............ 9

Scanning Electron Microscopy............. 9

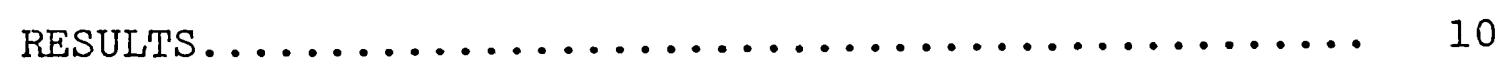

Histochemical Observations................ 10

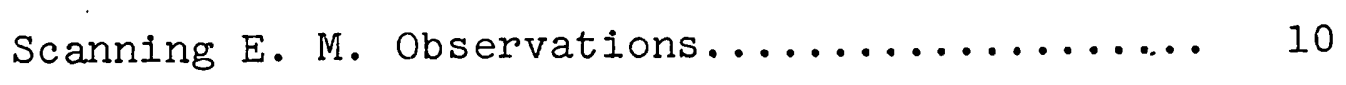

Chemical and Enzymatic Observations........... 13

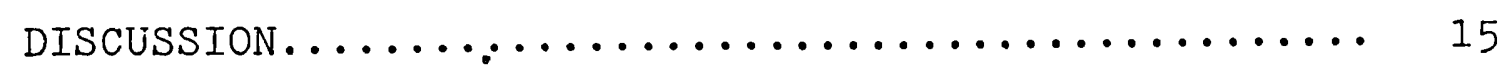

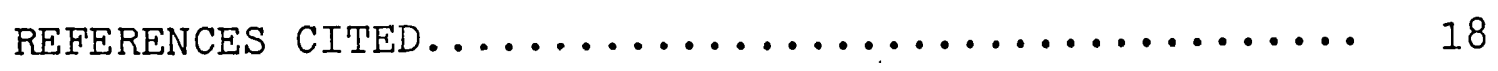




\section{LIST OF FIGURES}

\section{FIGURE}

1 Scheme for the extraction of polysaccharides.. 4

2 Flow chart for the extraction of pectic materials...................... 7

3 S.E.M. of freshly fired dwarf mistletoe seed $(25 \mathrm{X}) \ldots \ldots \ldots \ldots \ldots \ldots \ldots \ldots \ldots \ldots \ldots \ldots \ldots$

4 S.E.M. showing filamentous strands at higher magnification................. 12 


\section{INTRODUCTION}

Dwarf mistletoes (Arceutinobium spp.) are pathogens which have a serious economic impact on coniferous forests, especially in the western portion of North America. Interest in developing effective control measures has stimulated research into the biology of these hemiparasites.

Dwarf mistletoes are true flowering plants and as such have fruits with seeds. The "seeds" are so unusual that the term must be used with reservation. In contrast to true seeds, those of Arceuthobium have no seed coats or integuments but are only a naked embryo and endosperm encased in the endocarp of the fruit (Gill 1935). At maturity the seeds are explosively fired from the fruits for distances up to 50 feet, although the average distance is considerably less (Hawksworth and Wiens 1972).

After expulsion, the fresh seeds are coated (except for the basal end) with a mucilagenous substance called viscin. Running through the mucilage are a large number of filamentous strands which are attached to the distal and lateral parts of the seed. These strands are considered to be the remnants of cells which are presumed to secrete the viscin and are termed "viscin cells" (Kuijt 1969). The viscin enables the seed to stick to surfaces on which it lands after expulsion. Also, since the viscin is hygroscopic it is thought to play a part in supplying water necessary for germination (Gill 1935; Pierce 1905). During wet periods the viscin coat imbibes water and the seed 
becomes surrounied by a jelly-like mass which allows the seed to slip down to the axil of the leaf or fasicle on which it may have landed (Kuijt 1960). Such a placement is of primary importance for penetration and entry of the radicle into the host tissue.

To date, no studies have been done to indicate the nature of viscin from dwarf mistletoes. The purpose of the present investigation is to determine quantitatively the biochemical composition of the viscin from Arceuthobium tsugense (Rosendainl) Jones (Hawksworth and Wiens 1970). 


\section{MATERIALS AND METHODS}

\section{Seed Collection}

Seeds of $A$. tsugense were collected from infected Tsuga heterophyla (Raf.) Sarg. in late August and early September of 1974 at Goat Mountain (Sec. 11, T. 5S., R. 8E., Willamette Meridian) in the Mt. Hood National Forest. The fruits were mature and ready to fire the seeds. At a given collection site entire aerial shoots were picked by hand and placed in a paper bag. Subsequently the bags were shaken to cause the seeds to fire from the fruits. Fired seeds were then collected from the paper and aerial shoots with forceps and put in glass Petri dishes for storage in a refrigerator at $10^{\circ} \mathrm{C}$ for at least one week before use.

\section{Localization of Carbohydrates in the Viscin Layer}

Carbohydrates of the viscin layer were localized using a modification of a method by Jensen (1960). Individual seeds were placed in each of twelve $10 \times 75 \mathrm{~mm}$ test tubes. Three $\mathrm{ml}$ of distilled water were then added to each tube to allow complete hydration of the viscin material. By testing the rate of hydration, a one hour soaking time was found to be adequate. Excess water was removed with a narrow necked Pasteur pipette. At this stage, three tubes were set aside (Fj.g. I, I), the seeds still supporting the total insoluble carbohydrates found in the viscin layer.

To each of the remaining nine tubes were added $3 \mathrm{ml}$ of oxalate reagent which consisted of $0.5 \%$ (w:v) ammonium 


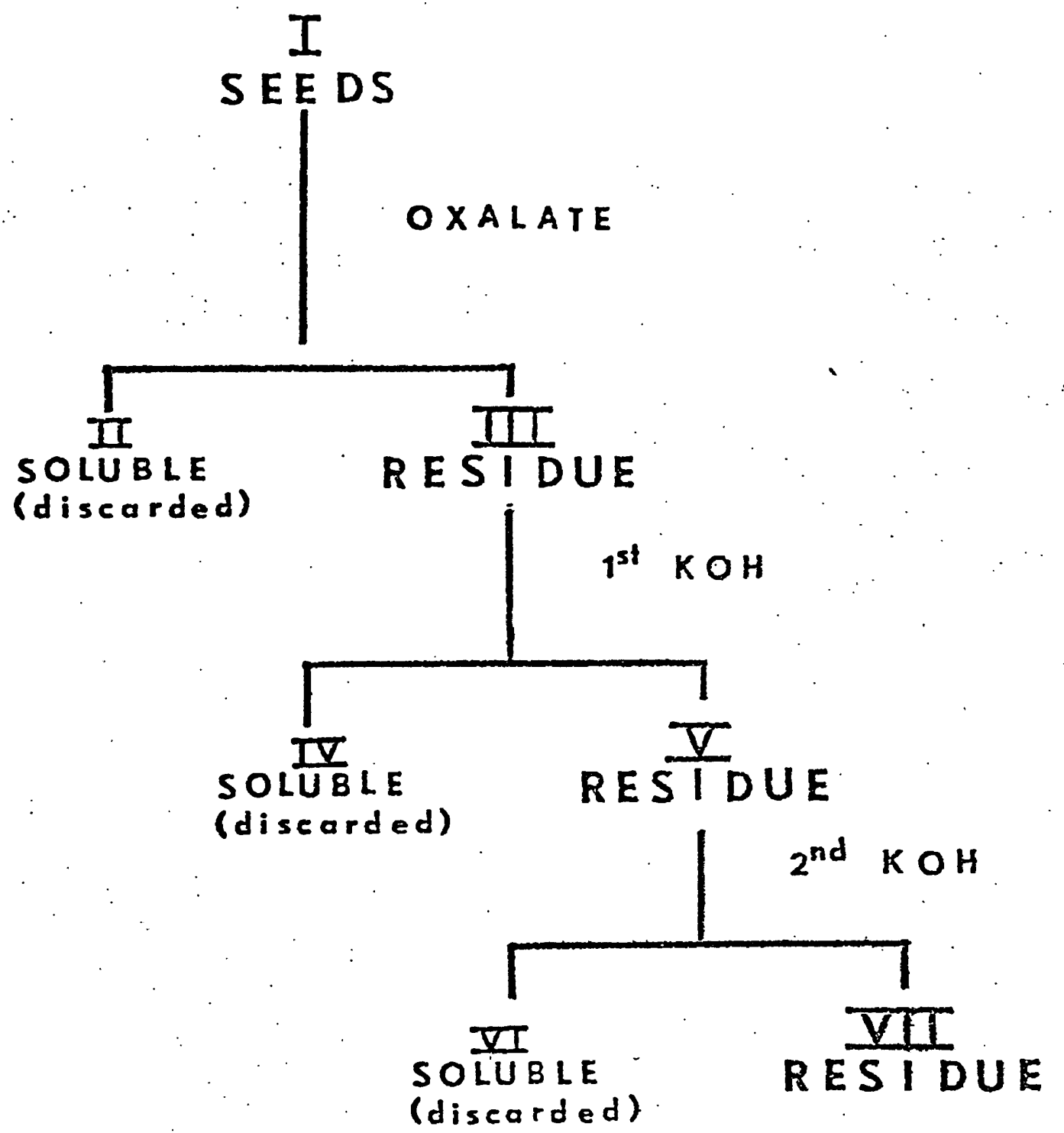

Figure 1. Scheme for the extraction of polysaccharides. The entire extraction procedure was done in triplicate. 
oxalate plus $0.5 \%$ axalic acid $(w: v)$. The tubes were incubated at $90^{\circ} \mathrm{C}$ for 12 hours (Fig. I. I). The oxalate reagent removes pectic substances (Jensen 1960). Following incubation the oxalate reagent was discarded with a Pasteur pipette and the seeds were rinsed with distilled water. Three tubes were set aside at this stage for subsequent histochemical tests (Fig. I, III).

To each of the remaining six tubes were added $3 \mathrm{ml}$ of 4\% (w:v) $\mathrm{KOH}$ and these were incubated for twelve hours at $25^{\circ} \mathrm{C}$ to remove hemicelluloses (Jensen 1960) (Fig. 1, V). After incubation the $\mathrm{KOH}$-hemicellulose extract was removed with a Pasteur pipette and discarded. Three tubes were set aside and the last three tubes were incubated in $17.5 \%$ (w:v) KOH $(3 \mathrm{ml})$. This final treatment is reported to remove any non-celluiosic polysaccharides that might have remained during prior extractions (Jensen 1960): It is generally acknowledged (Jensen 1960) that cellulose is the only common extracelluiar polysaccharide present after the $17.5 \%$ $\mathrm{KOH}$ extraction (Fig. I, VII).

Histochemical Reactions

Each set of three tubes from the above reactions was subjected to the following tests:

1. One tube from each set was tested for total carbohydrates using the Periodic Acid-Schiff's (PAS) reaction (Hotchkiss 1948; McManus, 1948).

2. One tube from each set was tested for pectins 
using the Hydroxylamine-ferric chloride (HFC) reaction (Reeve 1959).

3. One tube from each set was tested for cellulose using the Zinc-chlor-iodide (ZCI) reaction (Rawlins and Takahashi 1952).

\section{Isolation of Pectic Substances}

Two procedures were employed in the extraction and isolation of the pectic substances. These are summarized in Figure 2. One procedure used $0.5 \%$ ammonium oxalate plus $0.5 \%$ oxalic acid in the extraction (Anderson and King 1961a, 1961b) and the other used hot water (Jermyn and Isherwood 1956; Ray and Rottenberg 1964). Except for the above solvents both procedures were identical.

Previously refrigerated seeds were placed in two 50 $\mathrm{ml}$ vials, 100 seeds in each vial. The seeds were subjected to four successive extractions, two hours each in length, by continually shaking them in $25 \mathrm{ml}$ of oxalate solution in one vial and hot water in the other. Both the oxalate reagent and the water were heated to boiling before addition and allowed to cool during the treatment. Fresh solution was added prior to each treatment. The hot water extracts were combined and the oxalate extracts were combined and each was filtered through Whatman's No. 1 filter paper and then dialized for 48 hours against 6 changes of tap water. Ninety-five percent ethanol ( 1.5 vol.), $0.05 \mathrm{~N}$ with respect to HCl, was added to each of the above (Fig. 2, F) and the 


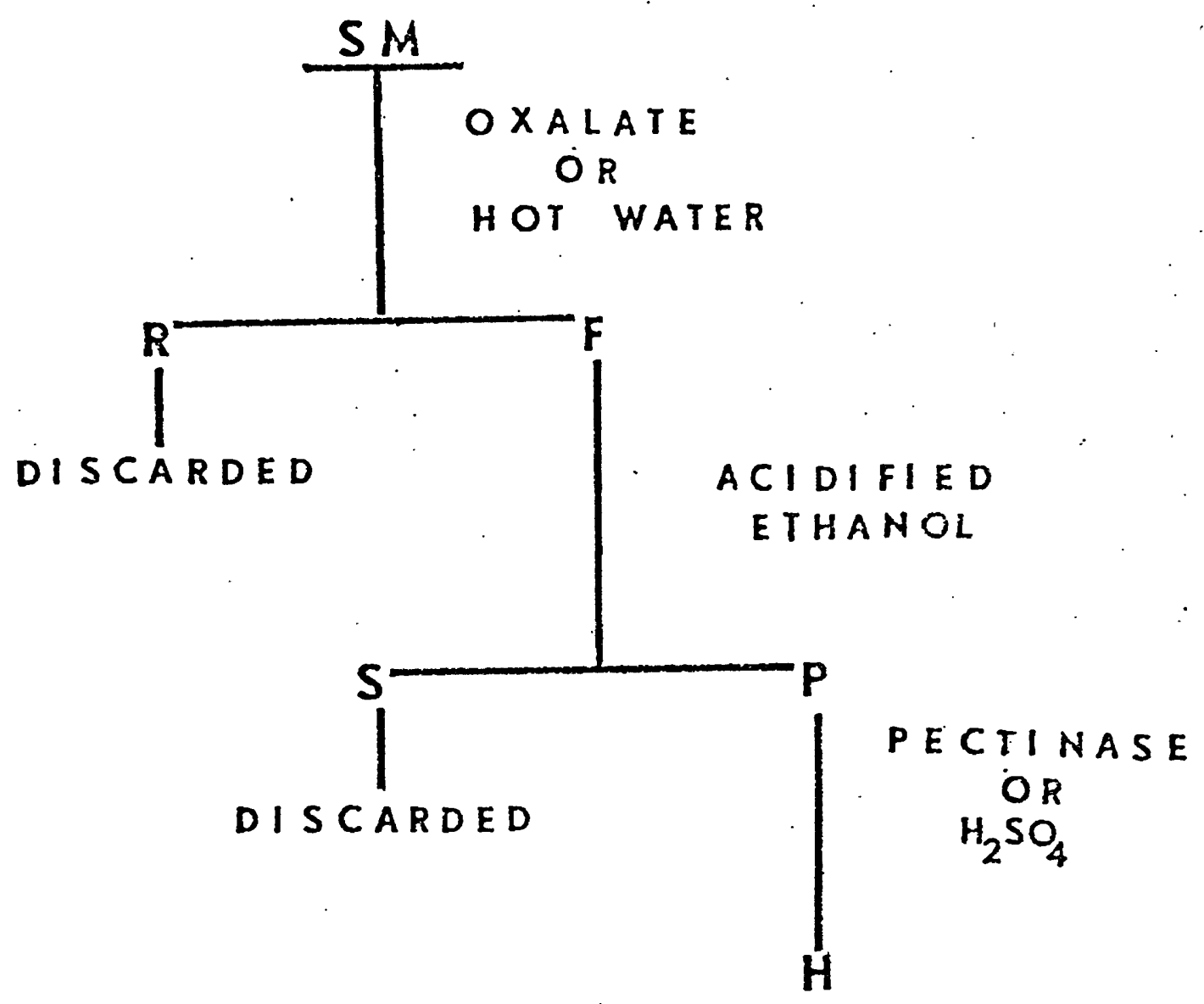

Figure 2. Flow chart for the extraction of pectic materials. SM, starting material ( $A$. tsugense seeds); $F$, filtrate; $R$, residue; $P$, precipitate; $S$, supernatant; $H$, hydrolysate. 
resultant precipitate (Fig. 2, P) was collected after 30 minutes of centrifugation at $5000 \mathrm{~g}$ and washed successively with $0.01 \mathrm{M}$ hydrochloric acid, $60 \%$ ethanol, and absolute ethanol (Milner and Avigad 1972). The resulting residue was then freeze-dried.

Determination of Hexuronic Acid

The hexuronic acid content of viscin extracts was determined colorometrically by the carbazole-sulfuric acidborate method (Bitter and Muir 1962). The reaction was carried out at $55^{\circ} \mathrm{C}$ according to the modification of Knutson and Jeanes (1968).

Enzymatic Hydrolysis

The enzymatic hydrolysis of freeze-dried pectic material from the alcohol precipitate (Fig. 2, P), was achieved with $20 \mathrm{mg}$ of commercial pectinase (Sigma). The reaction was carried out in $10 \mathrm{mI}$ of $0.05 \mathrm{M}$ acetate buffer at $\mathrm{pH} 5.0$ for 48 hours at $21^{\circ} \mathrm{C}$ (Milner and Avigad 1972). For comparison, samples of commercial citrus pectin and pure polygalacturonic acid (both from Sigma) were hydrolyzed in like manner.

\section{Acid Hydrolysis}

The acid hydrolysis of $50 \mathrm{mg}$ of freeze-dried pectic material from the alcohol precipitate (Fig. 2, P), was achieved with $100 \mathrm{ml}$ of $\mathrm{I} \mathrm{N} \mathrm{H}_{2} \mathrm{SO}_{4}$. The solution was placed 
In the autoclave for 3 hours at 20 pounds pressure $\left(121^{\circ} \mathrm{C}\right)$. Neutralization of the solution was carried out by adding a slight excess of $\mathrm{Ba}(\mathrm{OH})_{2}$ to the cooled hydrolysate.

\section{Paper Chromatography of Sugars}

Hydrolyzed extracts were separated by descending paper chromatography on 3 M No. 3 chromatography paper, with 160:40 isopropanol-water as the developing solvent. Benzidine reagent was employed for the detection of spots (Smith 1960). The same procedure was used for the examination of neutral sugars used as standards.

\section{Scanning Electron Microscopy}

Seeds of $A$. tsugense were prepared for scanning electron microscopy by gluing fresh, viscin-coated seeds onto specimen stubs with Duco (DuPont) cement, drying them and coating them with gold. Polaroid micrographs were taken on a Cambridge Stereoscan Scanning Electron Microscope. 


\section{RESULTS}

Histochemical Observations

All seeds supporting the total polysaccharides of the viscin layer (Fig. I, I) gave positive reactions for total carbohydrates, pectins and cellulose. The entire viscin layer tested positively for total carbohydrates by the PAS reaction and positively for pectins by the HFC reaction. According to the ZCL test, only the filamentous strands in the viscin contained cellulose.

The seeds treated to remove only pectic substances (Fig. 1, III) were devoid of the outer mucilagenous viscin coating. Only the filamentous strands remained and these tested positively for cellulose by the $\mathrm{ZCL}$ reaction. The tests for pectic substances (HFC) was negative.

The set of seeds treated to remove hemicellulose (Fig. I, V) and the final set in which only cellulose remained (Fig. 1, VII) gave precisely the same results with the histochemical tests as those treated to remove pectic substances (Fig. I, III).

These observations indicated that the viscin of $A$. tsugense is made up of two components: the gelatinous matrix of pectic substances and filamentous strands of cellulose.

Scanning E. M. Observations

Scanning electron micrographs of freshly fired seeds (Fig. 3 and 4 ) show that the long filamentous strands are 


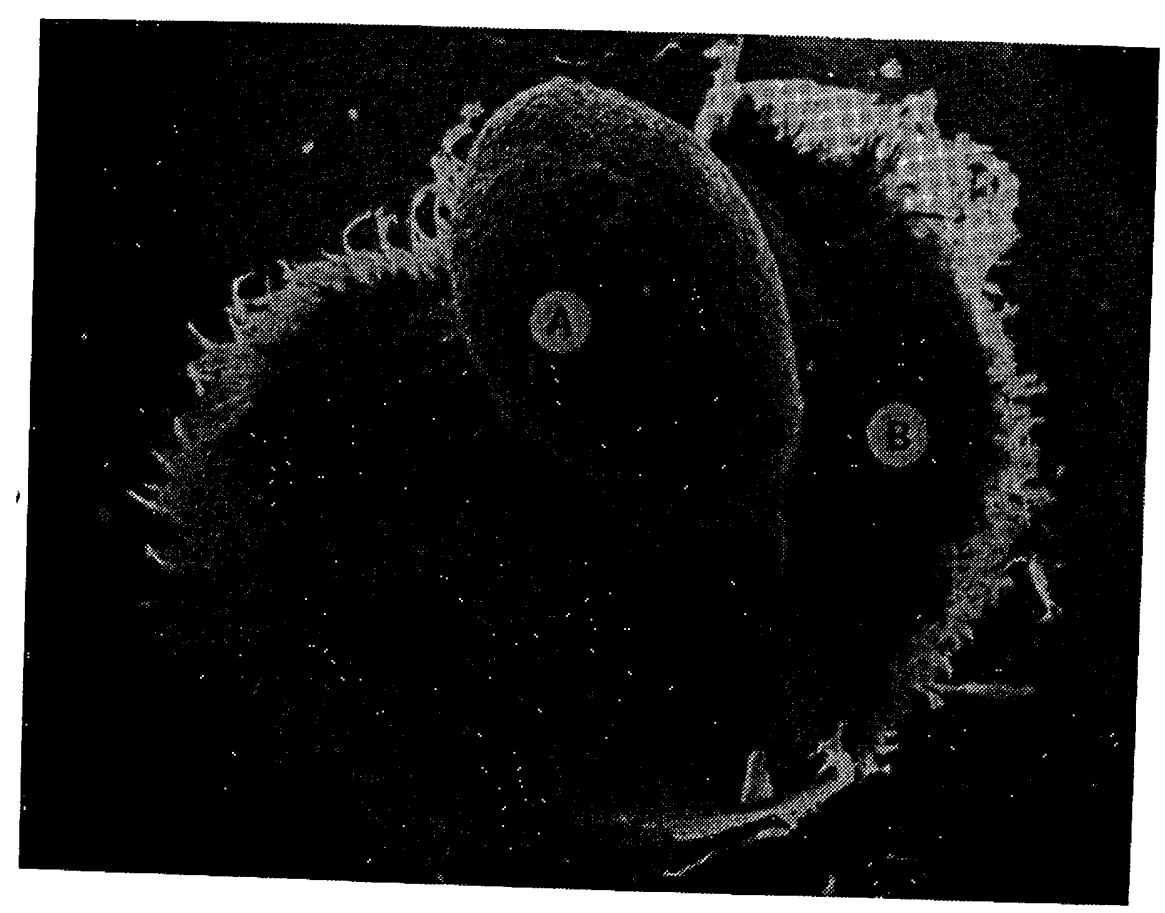

Figure 3. S.E.M. of freshly fired dwarf mistletoe seed (25X). A. "Seed" surrounded by viscin pectic material and embedded filamentous strands. B. Viscin material attached to substrate and being held in place by filamentous strands. 


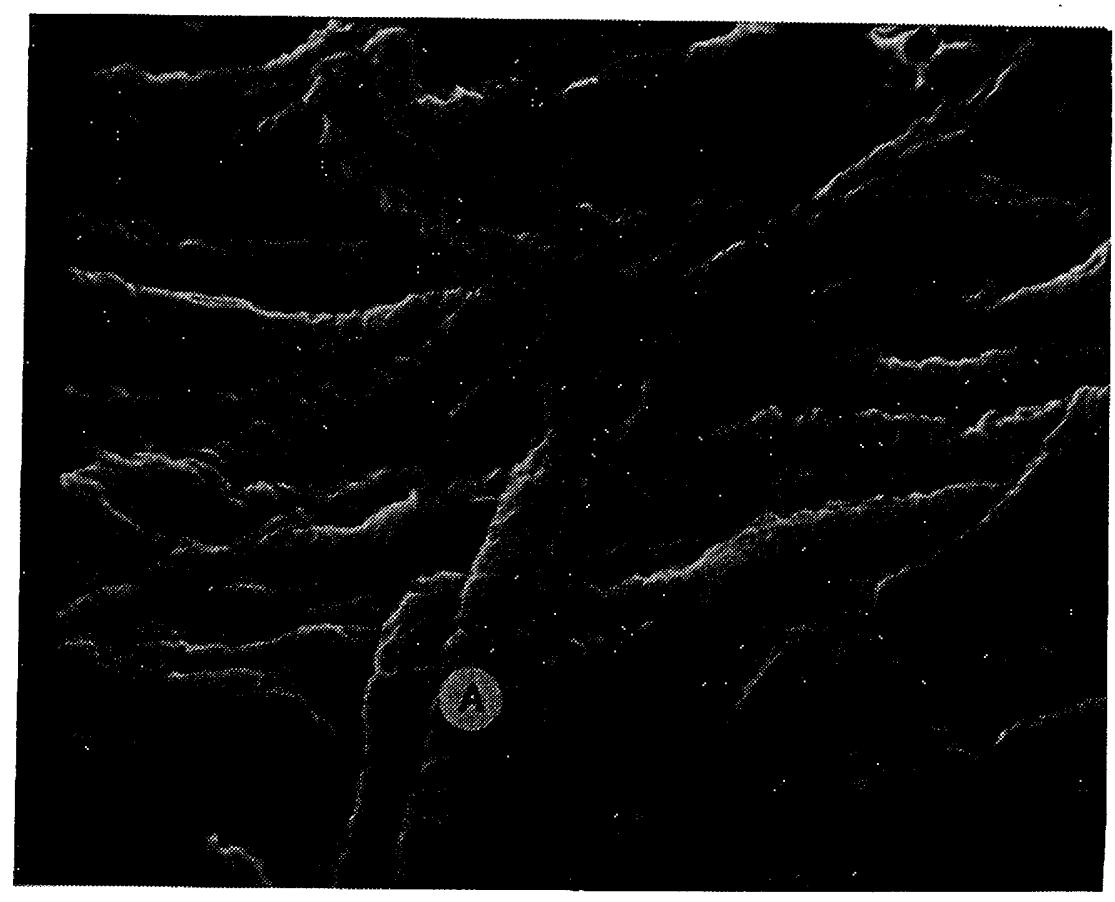

Figure 4. S.E.M. showing filamentous strands at higher magnification (1000X). A. Note helical substructure present in strands. 
embedded in the pectin matrix (Fig. 3). Higher magnification reveals that these strands have a helical substructure and are thought to be the thickened primary walls of the "viscin cells" which are dead at maturity (Kuijt 1960).

Chemical and Enzymatic Observations

Determination of hexuronic acid by the carbazole method showed no appreciable difference in total hexuronic acid between the dialyzed oxalate extracts and the dialyzed water extracts (Fig. 2). Therefore, all further tests were performed using the water extracts. Results from the carbazole tests showed that the water extracts contained 0.11 $\mathrm{mg}$ of hexuronic acid per $\mathrm{ml}$ of extract or $0.11 \mathrm{mg}$ of hexuronic acid per seed. Carbazole analysis of the filtrate (Fig. 2, F) showed that $92 \%$ of total hexuronic acid was precipitated by the acidified ethanol.

Ultimately a mass extraction of 5000 seeds (weight estimate) was carried out to obtain sufficient material for enzymatic and acid hydrolysis. The pectinase hydrolysis was carried out simultaneously on viscin precipitate and the commerical pectin and polygalacturonic acid. The products of enzymatic hydrolysis of viscin precipitates had the same chromatographic mobility as those of oligo-Dgalacturonic acids obtained from the hydrolysis of polygalacturonic acid and commercial citrus pectin. No spots representing other sugars were observed. 
Neutralized acid hydrolysates of the mistletoe pectic substances were also chromatographed. These gave only a single spot which had the same mobllity as D-galacturonic acid. No other sugars were found to be present. 


\section{DISCUSSION}

The formation of water soluble pectic substances is a well documented phenomenon in ripening fruits (Doesburg 1974). The exact mechanism is not well understood but the following statements are generally held to be true. During ripening, protopectin of the mesocarp is converted enzymatically into soluble pectinic acid which causes a scftening of the tissues due, in part, to the dissolution of the protopectic intercellular cement (Doesburg 1974).

Accepting Gill's (1935) conclusion that the immature viscin cells of dwarf mistletoe fruits represent the mesccarp, then my data suggest that viscin is the soluble pectinic acid residue resulting from an enzymatic conversicn of protopectin within this tissue. This conclusion is further supported by my SEM work which shows the breakdown of the helical thickenings in the primary walls of the viscin cells and their apparent disjunction due to lack of intercellular cement.

The hygroscopic nature of pectinic acid can also account for other observed properties of viscin. The increase in internal pressure that allows the seeds to be fired could result solely from the capacity of the pectin to imbibe large quantities of water. The above does not support the ideas of Pierce (1905) and Heinricher (1915) who proposed that the internal pressure was due to the ability of the viscin cells to absorb water. 
The viscin's capacity to undergo periodic drying and rehydration can also be accounted for by its pectic properties. My freeze-dried samples were able to undergo rehydration and maintain the same properties of viscosity and tackiness as fresh samples. The fact that this capacity is lost in natural situations after relatively short periods of time could be attributed to bacteria, fungi, ultraviolet light, or other naturally occurring factors which might contribute to degradative chemical reactions. Under laboratory conditions the seeds retain this capacity after as many as 100 wettings and dryings (Knutson 1973, and recent personal communication).

I postulate that the cellulose strands, act as a substrate for the viscin so that it remains firmly attached to the seed. Without these strands the viscin would likely be dissolved from the seeds quite quickly during periods of wetness. Due to their attachment to the seed at only the distal and lateral surfaces these cell fragments also serve to orient the seed as the viscin becomes dried out. Penetration into the host is thus facilitated (Kuijt 1960).

This study has answered a number of questions about the chemical nature of viscin. Future studies, utilizing mistletoe fruits at various stages of maturity would be highly enlighting both as a means of determining the biochemical precursors of the viscin and as a possible means to further elucidate the biosynthetic pathways leading to 
the production of pectic substances. 
Anderson, D. M. W. and N. J. King. 1961. Polysaccharides of the Characeae. and II. 1961a. The carbohydrate content of Nitella translucens. Biochim. Biophys. Acta, $52: 441-449$. and III. The carbohydrate content of Chara australis. Biochim. Biophys. Acta, 52:449-454.

Bitter, T., and H. M. Muir. 1962. A modified uronic acid carbazole reaction. Anal. Biochem. 4:330-338.

Doesburg, J. J. 1974. The pectic substances. In: L. P. Miller, ed. Phytochemistry. Van Nostrand Reinhold Co., New York. Vol. I, 270-286.

Gill, L. S. 1935. Arceuthobium in the United States. Trans. Conn. Acad. Arts and Sci. 32:111-245.

Hawksworth, F. G., and D. Wiens. 1970. Biology and taxonomy of dwarf mistletoes. Ann. Rev. Phytopath. $8: 187-208$.

Hawksworth, F. G., and D. Wiens. 1972. Biology and classification of dwarf mistletoes (Arceuthobium). U. S. Dept. Agr. Handbook No. 401. $234 \mathrm{pp}$.

Heinricher, E. 1915. Die Keimung und Entwicklergsgeschichte der Wachaldermistel. Arceuthobium oxycedri, auf Grund durchgefuhrter Kulturen: geschildert. Sitzungsber. Akad. Wiss. Wien, Abt. I, $124: 319-352$.

Hotchkiss. R. D. 1948. A microchemical reaction re-: sulting in the staining of polysaccharide structures in fixed tissue preparations. Arch. Biochem.

Jensen, W. A:, and M. Ashton. 1960. The composition of the developing primary wail in onion root tip cells. I. Quantitative analyses. Plant Physiol. 35: 313-323.

Jermyn, M. A., and F. A. Isherwood. 1956. Changes in the cell wall of pear during ripening. Biochem. J. $64: 123-132$. 
Knutson, C. A., and A. Jeanes. 1968. A new modification of the carbazole analysis: Application to heteropolysaccharides. Anal. Biochem. 24:470-481.

Kuijt, J. 1960. Morphological aspects of parasitism in the dwarf mistletoes. U. of Calif. Pub. in Botany $30: 337-436$.

Kuijt, J. 1969. The biology of parasitic flowering plants. U. of Calif. Press, Berkeley, Calif.

McManus, J. F. A. 1948. Histological and histochemical uses of periodic acid. Stain Technol. 23:99-108.

Milner, $Y$. and G. Avigad. 1972. The preparation of ${ }^{14} \mathrm{C}$ labeled pectic acid and D-galacturonic- $14 \mathrm{C}$ acid. Carbohyd. Res. 25:153-160.

Pierce, G. J. 1905. The dissemination and germination of Arceuthobium occidentale. Eng. Ann. Bot. 19:99-113.

Rawlins, T. E., and W. N. Takashi. 1952. Techniques of plant histochemistry and virology. National Press, Millbrae, Calif.

Ray, P. M. and D. A. Rottenberg. 1964. Uronic acid constituents of oat coleoptile cell walls. Biochem. J. 90:646-655.

Reeve, R. M. 1959. A specific hydroxylamine-feric chloride reaction for histochemical localization of pectin. Stain Technol. 34:209-211.

Smith, I. 1960. Chromatographic and electrophoretic techniques. Vol. I. Chromatography. Interscience Pub., New York. 